\title{
Dengue Encephalitis in a Newborn
}

\author{
Shilpa U. Kalane ${ }^{1}$ (D) $\cdot$ Asha N. Gokhale ${ }^{2}$. Umesh D. Kalane ${ }^{3}$
}

Received: 30 March 2021 / Accepted: 27 April 2021 / Published online: 20 May 2021

(C) Dr. K C Chaudhuri Foundation 2021

To the Editor: We present a case of a female neonate born at $36^{5 / 7}$ wk (birth weight $2.4 \mathrm{~kg}$ ). Mother had fever $1 \mathrm{~d}$ prior and was tested positive for NS1 antigen. The neonate had transient tachypnea of newborn. At $72 \mathrm{~h}$, she had fever $101^{\circ} \mathrm{F}$ with generalized diffuse erythematous, maculopapular, blanchable rash. The baby did not have fever thereafter. However, she suffered gastrointestinal bleeding by $86 \mathrm{~h}$ of life. The neonate was tested positive for NS1 (95.07 units); deranged platelets and a PTT normalized by day 10 . On day 6 , the neonate had generalized tonic convulsions. Neurosonography, septic screen, and serum biochemistry were normal. EEG showed seizure activity with abnormal background, while cerebrospinal fluid (CSF) examination was suggestive of meningitis (cells 23 , lymphocytes $2 \%$, neutrophils $46 \%$, proteins $123 \mathrm{mg} / \mathrm{dL}$, and sugar $49 \mathrm{mg} / \mathrm{dL}$ ). Blood as well as CSF were positive for dengue IgM antibody (1.974 and 2.502, respectively). Clinical, blood and CSF findings were supportive of dengue encephalitis. The baby was discharged on day 15 and was exclusively breast-fed. Her growth and developmental milestones at $18 \mathrm{mo}$ are appropriate for age.

Neonatal dengue has been reported in literature [1]. Denguerelated neurological complications have progressively been reported in pediatric and adult population [2]. The present case fulfilled the criteria for dengue encephalitis - the neonate had fever, neurological deterioration in the form of seizures, positive serology for NS1 antigen, DENV IgM antibody, and presence of DENV IgM antibody in CSF; other causes for encephalitis were ruled out by appropriate investigations [3]. The prognosis varied based on neurological complication [2, 3]. In the present case, the neurological manifestations were treated with supportive management in the form of phenobarbitone and IVFs. The neonate recovered gradually without any neurological sequelae. We conclude that CSF study must be done in all neonates with confirmed dengue infection. Management of dengue encephalitis remains supportive.

\section{Declarations}

Conflict of Interest None.

Informed Consent A full and detailed consent was obtained from the patient/guardian. The patient's identity has been adequately anonymized.

\section{References}

1. Haryanto S, Yohan B, Santoso MS, et al. Clinical features and virological confirmation of perinatal dengue infection in Jambi, Indonesia: a case report. Int J Infect Dis. 2019;86:197-200.

2. Pancharoen C, Thisyakorn U. Neurological manifestations in dengue patients. Southeast Asian J Trop Med Public Health. 2001;32:341-5.

3. Soares C, Puccioni-Sohler M. Dengue encephalitis: suggestion for case definition. J Neurol Sci. 2011;306:165.

Publisher's Note Springer Nature remains neutral with regard to jurisdictional claims in published maps and institutional affiliations.

Shilpa U. Kalane

drshilpakalane@gmail.com

1 Department of Neonatology, Deenanath Mangeshkar Hospital, NICU, 3rd Floor, SS Building, Pune, Maharashtra 411004, India

2 Department of Obstetrics \& Gynecology, Deenanath Mangeshkar Hospital, Pune, Maharashtra, India

3 Department of Pediatric Neurology, Deenanath Mangeshkar Hospital, Pune, Maharashtra, India 